\title{
The Ergonomics Analysis In the Process of Reversed Loader Cylinder Virtual Assembly Based on CATIA and DELMIA
}

\author{
Di Liang ${ }^{1, a}$, Gui Zhi Sun ${ }^{1, c}$, Shuang $\mathrm{Wu}^{1, \mathrm{~b}}$ \\ ${ }^{1}$ School of Mechanical Engineering, Shenyang University, Shenyang, Liaoning Province, China
}

\begin{abstract}
Health and work efficiency of staff of the enterprise gradually attracted people's attention. The human factor was crucial in the manufacturing process. First establish virtual assembly model through CATIA software. Second use DELMIA software to make the rapid upper limb assessment of human body posture, lifting equation NIOSH to lift frequent location analysis, etc. Improve the unreasonable location for the improvement of human factors engineering to reduce the probability of enterprise staff occupational disease and injury, and eventually improve production efficiency.
\end{abstract}

\section{Introduction}

Currently, various large-scale machinery manufacturing industry continues to develop. Among them, the people and systems closely is particularly important, Accident hazards and personnel injury caused by the human factor is more cause for concern ${ }^{[1]}$. Domestic and foreign scholars conducted in-depth research of ergonomics analysis under virtual assembly, Washington State University integrated a fast upper assessment algorithm in VADE system, the study of ergonomics and virtual assembly made simple binding ${ }^{[2,3]}$. US State University system raised JIGORO system, the system made twodimensional model of the product model import a virtual assembly under requirement environmental, to made modeling and simulation of virtual assembly process ${ }^{[4]}$. Yining Zheng and $\mathrm{Xin} \mathrm{Ru}$ carried on the interaction techniques research under the virtual assembly environment human-computer ${ }^{[5]}$. Qian Sun put forward the virtual assembly technology based on DELMIA in aircraft assembly applications ${ }^{[6]}$.

This paper researched virtual assembly machine cylinder production process, it carried on the cylinders threedimensional modeling and simulation combined the CATIA software and DELMIA software.Do the manmachine operation modeling and simulation of production plant based on human factors engineering, and conduct ergonomics analysis and improvement. Better solve the problem of personnel injuries and occupational diseases, and have co-benefits with enterprise.

\section{Enterprise production status}

Company A newly introduced reproduced oil cylinder production workshop, new model oil cylinder put into production. Production line stuck in the past on the basis

\footnotetext{
${ }^{a}$ Corresponding author: author@e-mail.org
}

of the product, poor management of production personnel, production site confusion, efficiency and production quality has been lacking. The introduction of new products to achieve better promote enterprise development purposes, the production plant is particularly important to improve.

In this paper, introduction of the oil cylinder as the main object, 3D model of each member, as shown in Figure 1..

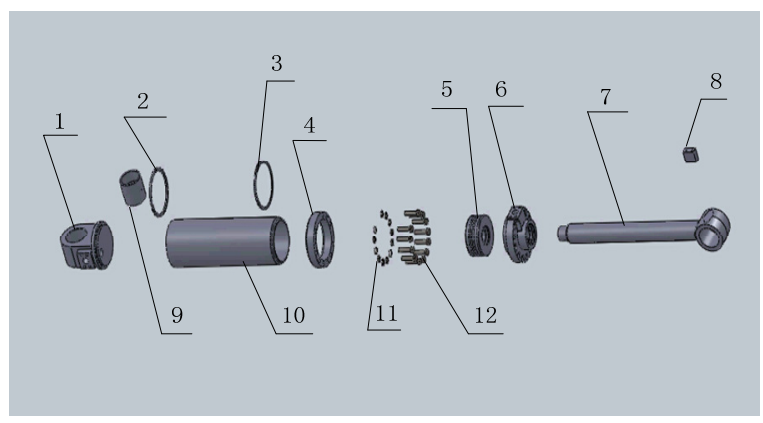

1-bottom, 2-bottom weld, 3-flange welds, 4-flanges, 5pistons, 6-guide sleeve, 7-rod, 8-seat, 9-bushing, 10cylinder, 11-washers, 12-screws

\section{Oil cylinder Model and Virtual Assembly}

This paper modeling the main components of the hydraulic oil cylinder with CATIA, as shown in Figure 2.

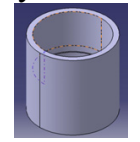

(1)

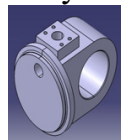

(2)

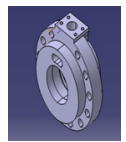

(3)

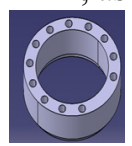

(4)

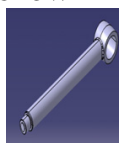

(5)

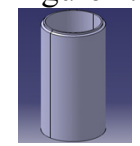

(6) 
(1) - bushing (2) - bottom (3) - guide sleeve (4)flanges(5) - rod (6) - cylinder

Figure2. The main components

Virtual assembly simulation of hydraulic cylinders, specifically including tracking command activation, compass for disassembly of parts and paths recorded.Use recorder records the assembly tree to generate the corresponding sequence, further editing the obtained three-dimensional animation of virtual simulation cylinders, as shown in Figure 3.

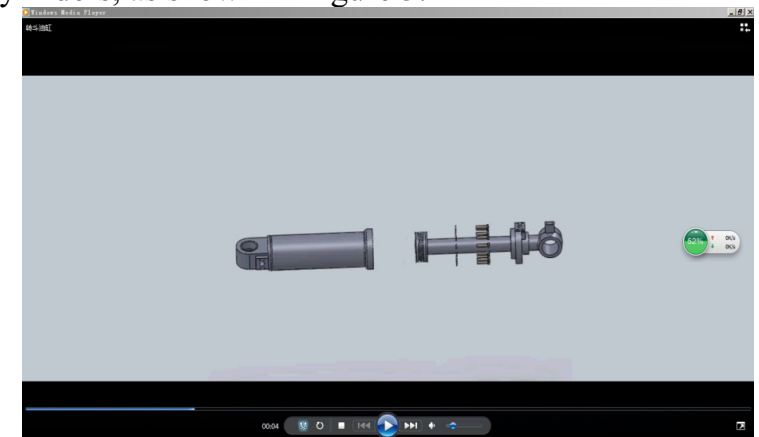

Figure3. The cylinder virtual assembly simulation animation

\section{Human factors analysis of key stations based on DELMIA}

\subsection{Create mannequins and mannequin task}

Mannequin libraries created based on the actual working conditions of staff of cylinder production plant, as shown in Figure 4.

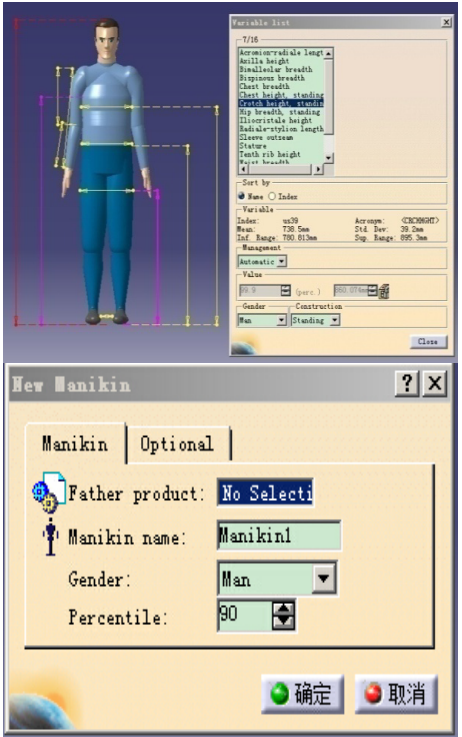

Figure4. The human body model in DELMIA

After the human body model, loading the movement to the process of the task within the human body model.

\subsection{Human Factors Analysis of key station based on DELMIA}

\subsubsection{The analysis that can reach envelope}

In virtual simulation, mannequin simulation action running, hand, eye area can be achieved by a spherical region indicates, as shown in Figure 5. If it can well cover parts or tools needed, described assembling good physical reachability, human factors analysis can be carried out. If it can not cover, the reachability is not ideal, make improvements. This paper studied stations were analyzed under the premise of good reachability, improvement for bad reachability stations, increase carts or pulley platform, better selection means or tools within reachability of range.

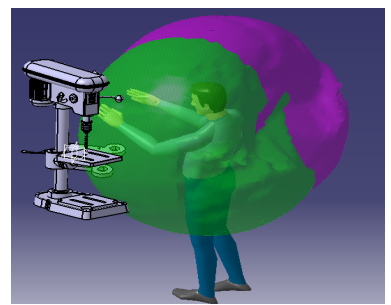

Figure5. The hand can reach envelope range

\subsubsection{RULA rapid analysis of upper limb}

Rapid upper limb Assessment used to assess the state of human upper limb in the job. For operations personnel to quickly assess the upper limb in the module of DELMIA, specifically as shown in Figure 6 and 7.

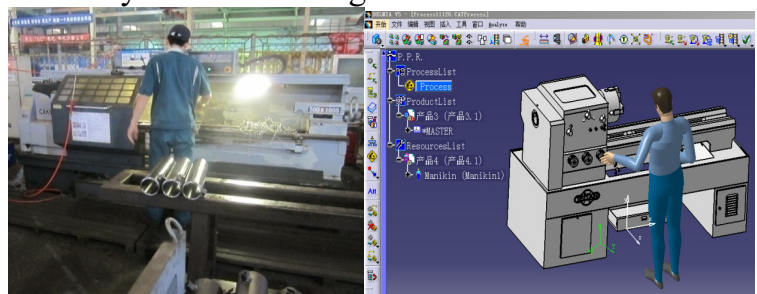

Figure6. Simulation and analysis of operations

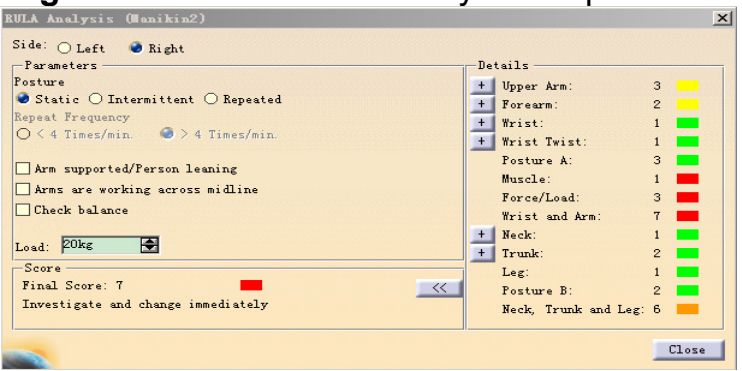

Fig7. The results of the analysis

The figure shows, 50th percentile for employee location for analysis, staff right arm comfort simulation analysis. When statically job, arm support, load $20 \mathrm{~kg}$. To maintain this position, RULA analysis of the resulting score of 7 . Posture require immediate research and changes in posture, specific improvements and analysis are shown in Table 1.

Table1. The evaluation analysis of upper limb

\begin{tabular}{|c|c|c|}
\hline Place & Scores & Improvement \\
\hline Upper arm & 3 & \multirow{10}{*}{$\begin{array}{l}\text { Upper arm, forearm etc within an } \\
\text { appropriate range, wrist twist reasonable } \\
\text { range, wrist and arm projects were } \\
\text { scores of } 7 \text {, harm to } \mathrm{IV} \text {, it should be } \\
\text { immediately improved, here can } \\
\text { increase the mechanical arm, reduce } \\
\text { static time of staff handheld parts, the } \\
\text { score of legs was } 6 \text {, recommend } \\
\text { personnel frequently changed in the } \\
\text { squat position the center of gravity foot, } \\
\text { to alleviate accumulated fatigue. }\end{array}$} \\
\hline Forearm & 2 & \\
\hline Wrist twist & 1 & \\
\hline $\begin{array}{c}\text { Wrist } \\
\text { muscles }\end{array}$ & 1 & \\
\hline $\begin{array}{l}\text { Wrist and } \\
\text { forearm }\end{array}$ & 7 & \\
\hline Wrist & 1 & \\
\hline Neck & 1 & \\
\hline Trunk & 2 & \\
\hline Legs & 6 & \\
\hline Total & 7 & \\
\hline
\end{tabular}




\subsubsection{NIOSH analysis of human body}

The personnel job activity analysis module of DELMIA software can carriy on upright row analysis, lifting analysis of job activities, as shown in figure 8 and 9 .
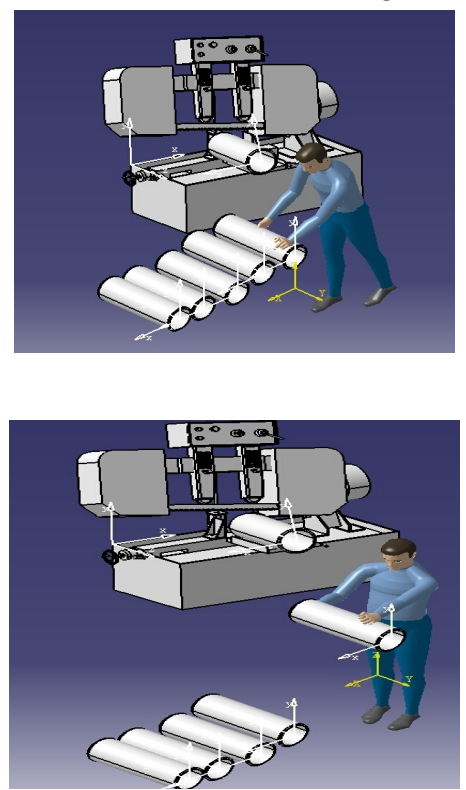

Fig8. Simulation and analysis of operations
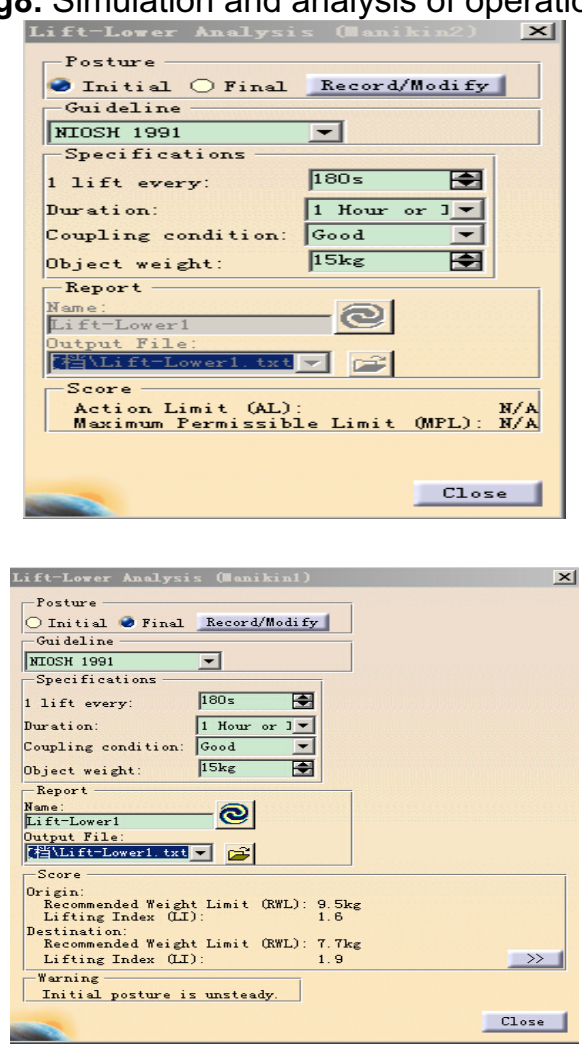

Fig9. Station posture analysis

Staff set the choice theory NIOSH1991 at the initial posture, upgrade once every 180s. Complete the work One hour a day, the results obtained in figure. Recommended the initial attitude of the limit weight was $9.5 \mathrm{~kg}$. This value represented, In the absence of dangerous situations, health workers lifted this limit weight and maintained for a period of time. The Lifting Index described the level of physical stress related parameters. When A was greater than 1, it would lead increasing probability of workers lower back muscle injury. The station should be adjusted, and increased robot or freighter platform, instead of the labor, reduced fatigue, improved production efficiency.

\subsubsection{Analysis of human handling}

Carrying Analysis Module is human factors design analysis module DELMIA software. This analysis gave two kinds of transport height. Male: the height of the ground to hand was set to 787.4 and 1117.6. Female: the height of the ground to the hand was set to 711.2 and 1041.4.Workstation analysis results were shown in Figure 10 :

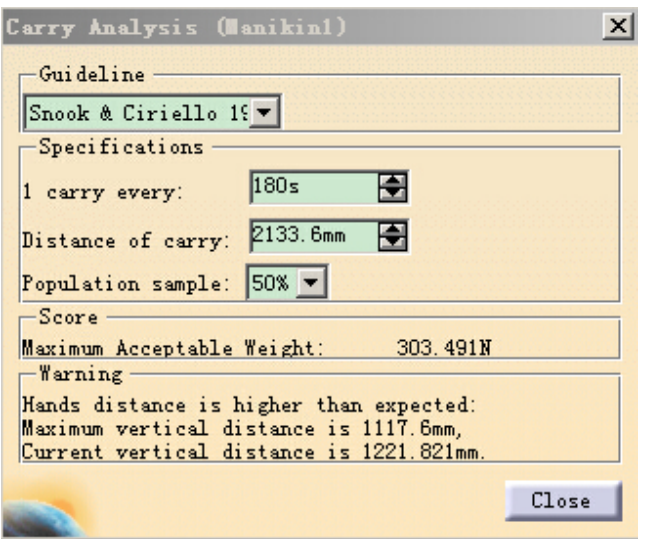

Fig10. Handling analysis results

Handling once every $180 \mathrm{~s}$, transport distance set $2133.6 \mathrm{~mm}$, 50th percentile manikin, on this basis, people in the security situation, the acceptable maximum carrying weight was $303.491 \mathrm{~N}$. Cylinder production plant portion station exceeds the standard, to make the appropriate improvements. For example, companies should outsource the handling device, to reduce injury and improve efficiency

\subsubsection{Body sliding analysis}

Under push forward working conditions, hand height was defined as three kinds, respectively, $635 \mathrm{~mm}, 889 \mathrm{~mm}$, and $1346.2 \mathrm{~mm}$. Driven distance previously set six kinds, respectively $2133.6 \mathrm{~mm}, 7620 \mathrm{~mm}, 15240 \mathrm{~mm}, 30480 \mathrm{~mm}$, $45720 \mathrm{~mm}$ and $60960 \mathrm{~mm}$. According to the above setting distance, Analyze the sliding body force of sawing work, it was shown in figure 11. Station sliding analysis: Push once every $600 \mathrm{~s}$, the distance of push and pull was $2133.6 \mathrm{~mm}$, fifty percent of people able to complete the task, this station maximum acceptable initial thrust was $423.103 \mathrm{~N}$, the maximum initial tension was $323.291 \mathrm{~N}$, The maximum acceptable thrust termination was 314.163 $\mathrm{N}$, The maximum pulling force termination was $262.287 \mathrm{~N}$. It is based on this data in the actual production process, to improve overload the station. 


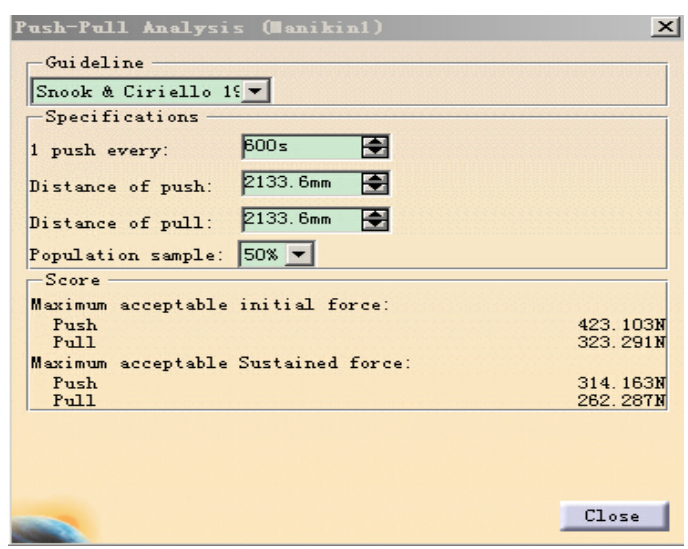

Fig11. The push and pull the analysis results 4.2.6 Biomechanical analysis of human

In this paper, make biomechanical analysis of part station in cylinder production plant and get biomechanical report results, summary analysis of its. As shown in Figure 12 analyzes the content of the specific.

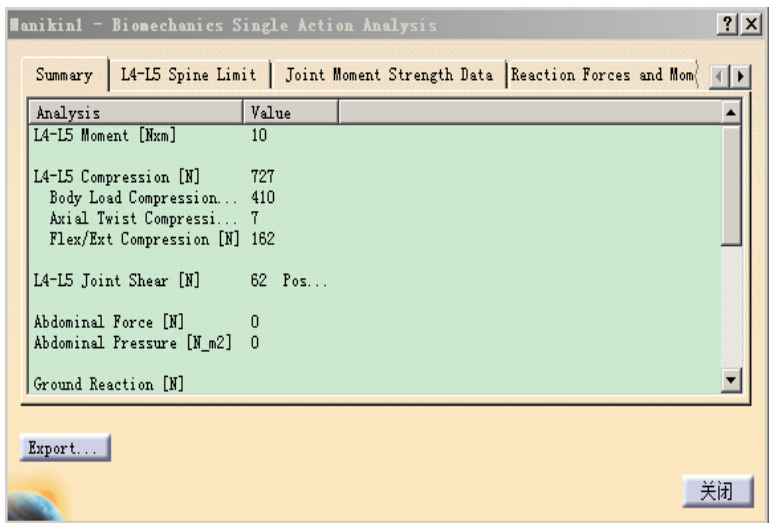

Fig12. Biomechanical analysis results of single action

The results show that the stress analysis of human body of the station, section $4-5$ of the spine torque is $10 \mathrm{~N} \cdot \mathrm{m}$ and pressure is $727 \mathrm{~N}$ and other data provide data to support the production process stress on the joints. Improve the stations of greater force on the joints and against the larger, provide valid data for the production.

\subsubsection{Analysis of human handling}

OWAS code staff working posture, including back coded, coded legs, shoulders coded, neck coded and loading coded, these five elements are combined, determining a working posture with the code. In order to better differentiate work posture degree, using different colors to distinguish different grades, as shown in Table 2.

Table2. OWAS working posture classification table

\begin{tabular}{|c|c|c|}
\hline Grade & Meaning & color \\
\hline I & $\begin{array}{c}\text { Not harmful to health, without } \\
\text { improvements }\end{array}$ & green \\
\hline II & $\begin{array}{c}\text { Harm is not obvious, suggested } \\
\text { improvements }\end{array}$ & yellow \\
\hline III & $\begin{array}{c}\text { Greater dangers, recommend short- } \\
\text { term improvements }\end{array}$ & orange \\
\hline IV & Great danger, stop job to adjust & red \\
\hline
\end{tabular}

OWAS analysis of the human body through different colors show up, as shown in Figure 13.

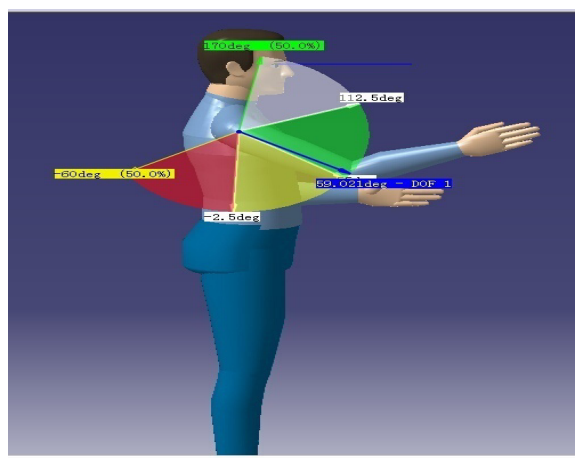

Fig13. OWAS analysis of right upper arm different comfort zones

\section{Conclusion}

First, use CATIA virtual to conduct cylinders assembly modeling analysis, stand up to demonstrate intuitively for cylinder process, lay the foundation of human factors engineering analysis. Second, carry on simulation for man-machine operation of cylinder production plant part station on based DELMIA software. Use simulation to get human factors engineering analysis results of each stage of production workers related operation. Further improve the unreasonable stations, to reduce worker injuries and occupational diseases related to the probability of the process

\section{References}

[1] Chenhui Jia. Digital factory manufacturing information integration platform based on [J].Management technology,2006,(7):103-106.

[2] Macatamney L, Corlett E N. RULA: a survey method for the investigation of work - related upper limb disorders [J]. Applied Ergonomics, 1993, 24(2): 91-99.

[3] Shaikh I, Kim Y J, Jayaram S, et al. Integration of immersive environment and rula for real - time study of workplace related musculoskeletal disorders in the upper limb. Proceedings of DETC' 03 ASME, Chicago, Illinois, 2003.

[4] Rajan V N, Sivasubramanian K, Fernandez J E. Accessibility and ergonomic analysis of assembly product and jig designs [J] .International Journal of Industrial Ergonomics, 1999, 23(5-6): 473-487.

[5] Yining Zheng, Xin Ru,Chengtong Tang.Humancomputer interaction research techniques under virtual assembly environment[J].Journal of Beijing institute of technology.2006,(26).

[6] Hui Zhang,Qian Sun,XiaoYu Wu.The virtual assembly technology based on DELMIA in aircraft assembly applications[J].Aeronautical Manufacturing Technology,2012,21:89-91. 